University of Nebraska - Lincoln

DigitalCommons@University of Nebraska - Lincoln

4-15-1987

\title{
Magnetic characteristics of ultrafine Fe particles reduced from uniform iron oxide particles
}

K. Bridger

Martin Marietta Laboratories, Martin Marietta Corporation, Baltimore, Maryland

J. Watts

Martin Marietta Laboratories, Martin Marietta Corporation, Baltimore, Maryland

M. Tadros

Martin Marietta Laboratories, Martin Marietta Corporation, Baltimore, Maryland

Gang Xiao

Johns Hopkins University, Gang_Xiao@brown.edu

Sy_Hwang Liou

University of Nebraska-Lincoln, sliou@unl.edu

See next page for additional authors

Follow this and additional works at: https://digitalcommons.unl.edu/physicsliou

Part of the Physics Commons

Bridger, K.; Watts, J.; Tadros, M.; Xiao, Gang; Liou, Sy_Hwang; and Chien, C.L., "Magnetic characteristics of ultrafine Fe particles reduced from uniform iron oxide particles" (1987). Si-Hwang Liou Publications. 13. https://digitalcommons.unl.edu/physicsliou/13

This Article is brought to you for free and open access by the Research Papers in Physics and Astronomy at DigitalCommons@University of Nebraska - Lincoln. It has been accepted for inclusion in Si-Hwang Liou Publications by an authorized administrator of DigitalCommons@University of Nebraska - Lincoln. 


\section{Authors}

K. Bridger, J. Watts, M. Tadros, Gang Xiao, Sy_Hwang Liou, and C.L. Chien 


\title{
Magnetic characteristics of ultrafine Fe particles reduced from uniform iron oxide particles
}

\author{
K. Bridger, J. Watts, and M. Tadros \\ Martin Marietta Laboratories, Martin Marietta Corporation, Baltimore, Maryland 21227 \\ Gang Xiao, S.H. Liou, and C. L. Chien \\ The Johns Hopkins University, Baltimore, Maryland 21218 \\ Uniform, cubic 0.05 - $\mathrm{m}$ iron oxide particies were formed by forced hydrolysis of ferric \\ perchlorate. These particles were reduced to $\alpha-\mathrm{Fe}$ by heating in hyorogen at temperatures \\ between 300 and $500^{\circ} \mathrm{C}$. The effect of reduction temperature and various prereduction \\ treatments on the microstructure of the iron particles will be discussed. Complete refuction to \\ $\alpha$-Fe was established by ${ }^{57} \mathrm{Fe}$ Mössbauer spectroscopy and $\mathrm{x}$-ray diffraction. Magnetic \\ measurements on epoxy and polyurethane films containing these particles with various mass \\ fractions gave coercivities as high as 1000 Oe. The relationship between the rnagnetic \\ measurements and the microstructure will be discussed. $\mathrm{Na}_{2} \mathrm{SiO}_{3}$ is found to be the best \\ coating material for the process of reducing iron oxide particles to tron.
}

\section{MTRODUCTION}

For high-density recording media, the development of material with high magnetization and coercive force is required. One of the best candidates is small iron particles. The pseudonorphic reduction of iron oxide particles to iron is an important process in the production of these materiais. Many workers have studied this process, with the objective of producing nonporous, single-domain iron particles. One of the major challenges has been the prevention of particie sintering. It is known that sintering tends to occur at reduction temperatures above $350^{\circ} \mathrm{C} .^{1}$ Additions of various dopants (e.g., silver, tin, and cobalt) have been proposed to minimize sintering. ${ }^{1,2}$ Other methods have included coating the oxide particles with barium dodecyl suffonate ${ }^{3}$ and silicic acid. ${ }^{4}$ The variation of porosity in the particles with dehydration temperature was also studied. ${ }^{4}$ It was found that on dehydration of $\mathrm{FeOOH}$, the starting oxide, porous hernatite particles were formed and that this porosity was carried over to the iron.

As part of an overall program studying the variation in magnetic properties of submicron iron particles with size and packing fraction we have prepared uniform, nonporous, cubic iron particles $\approx 0.05 \mu \mathrm{m}$ in size. In this paper we report the effects of reduction temperature and various coating materials on the particle morphology and magnetic properties. The study of nonporous cubic iron particles and the detailed preparation procedures will be presented elsewhere. ${ }^{5}$

\section{EXPERIM監NT}

The preparation of small iron particles was done as follows. First, uniform iron oxide particles were prepared by the forced-hydrolysis method. ${ }^{6}$ In the forced-hydrolysis method, acidic solutions of ferric salts are aged at elevated temperatures to promote hydrolysis of the ferric ion. This leads to nucleation and growth of oxide particles. Particle size and shape are controlled by the nature and concentration of the anion, reaction temperature, and the aging time. The iron oxide particles prepared by the method above were either freeze dried immediately or premixed with a coating material and then freeze dried. The coatings used include sodium silicate $\left(\mathrm{Na}_{2} \mathrm{SiO}_{3}\right)$, polyvinylaicohol (PVA), silicic acid, barium dodecyl sulfonate, and silica. The coating materials were added either as an aqueous solution (e.g., $0.1 \mathrm{M}$ or $0.001 \mathrm{MNa}_{2} \mathrm{SiO}_{3}, 0.1 \% \mathrm{PVA}_{\text {, }}$ or $0.001 \mathrm{M}$ silicic acid ) or as a dispersion (e.g, silica).

The freeze-dried powders were reduced under hydrogen in a tube furnace. Samples for magnetic characterization were carefully weighed in a glove box and then mixed with a known weight of a polyurethane or epoxy resin. The slurries thus formed were milled for $20 \mathrm{~min}$ in a small shaker (WiggL-bug) and were cast on microscope sides. The iron particles on the slides were characterized by $x$-ray diffraction, Mössbauer spectroscopy, and magnetization measurements. Samples for electron microscopy were prepared by first milling a quantity of powder in toluene and then dispersing the particles using an ultrasonic bath.

\section{RESULTS AND DISCUSSIOHS}

The effects of heat treatment on particle morphology are exceptionally important, especialiy in as far as the morphology changes affect magnetic properties. ${ }^{1,2,4,7}$ In general, sintering of the particles leads to lower coercivities and is thus undesirable. A number of pretreatments have been suggested to minimize this sintering. In the following, we discuss the effect of various coating materials as well as no coating and reduction temperature on the particle morphology and magnetic properties.

The particles before and after hydrogen reduction are routinely checked by x-ray, TEM, and Mössbauer spectroscopy. Mössbauer spectra on particles before hydrogen reduction show that $\alpha-\mathrm{Fe}_{2} \mathrm{O}_{3}$ is the only phase. The spectra show that the particles after hydrogen reduction are exclusively $\alpha$-iron with a phase purity $>95 \%$. This indicates that the hydrogen reduction process efficiently converts all oxide particles into $\alpha$-iron. Furthermore, the procedures for handing the iron particles, and the methods for dispersing the 

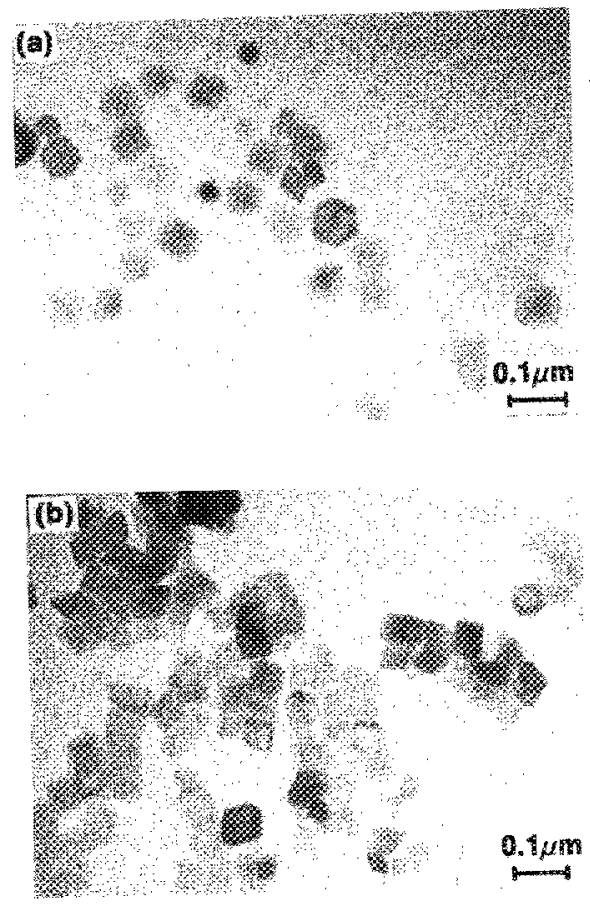

FIG. 1. TEM of uncoated (a) iron metal and (b) oxide particles.

iron particles are effective in preventing oxidation. This is significant because these particles are pyrophoric, i.e., they spontaneously ignite in air. No evidence of superparamagnetism was seen from the Mössbauer spectra and from the magnetic measurements.

Electron micrographs of a typical sample before and after reduction at $400^{\circ} \mathrm{C}$ are shown in Fig. 1. The cubic shape of the particles is maintained during the reduction process, and the sizes appear to be similar-at least to a first approximation. Electron diffraction patterns confirmed the $x$-ray diffraction analysis that the particles are indeed $\alpha$-iron.

Magnetic properties of specimens containing ultrafine iron particles depend on the size, shape, volume fraction, and dispersion of the particles. In this work great care has been taken to ensure a good dispersion of the iron particles in

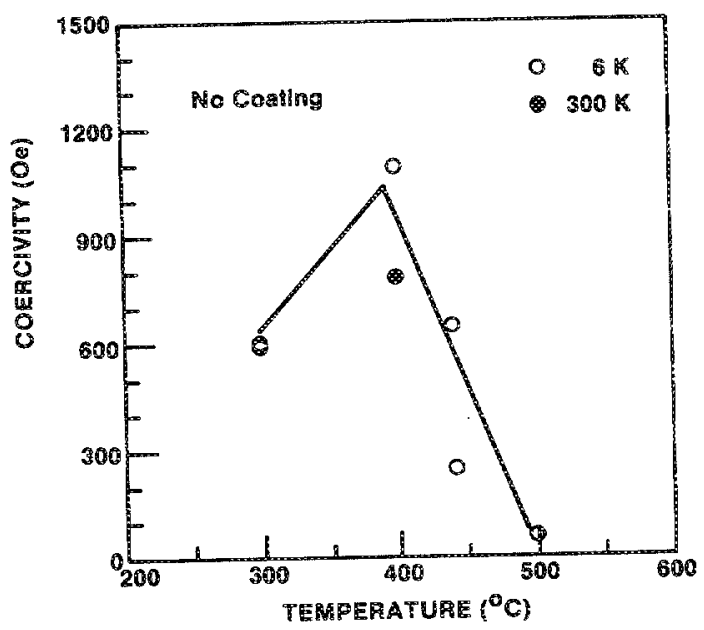

FIG. 2. Variation of coercivity of iron particles (uncoated) with reduction temperature.

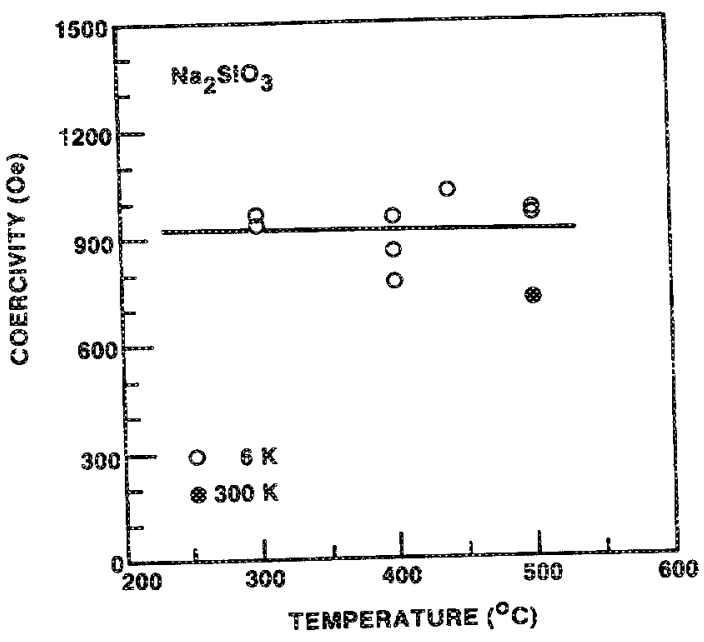

FIG. 3. Variation of coercivity of iron particles $\left(\mathrm{Na}_{2} \mathrm{SiO}_{3}\right)$ with reduction temperature.

a polymer film at a known mass fraction. Films with volume fraction less than $1 \%$ are used in the magnetic measurement. The coercivity of the uncoated particies versus reduction temperature is shown in Fig. 2. Initially $H_{\mathrm{c}}$ increased with increasing reduction temperature to about 1100 Oe at $400^{\circ} \mathrm{C}$. High values of $H_{c}$ around 1000 Oe are in keeping with the ultrafine $(<0.1 \mu \mathrm{m})$ nature of these particles. ${ }^{8}$ However, above $400^{\circ} \mathrm{C}$, the value of $H_{c}$ drastically decreased, and at $500^{\circ} \mathrm{C}, H_{c}$ is only $60 \mathrm{Oe}$, similar to the value for bulk iron. This drop-off in $H_{c}$ is indicative of substantial sintering between the particles occurring at the higher recuction temperatures. Indeed, we have observed sintering
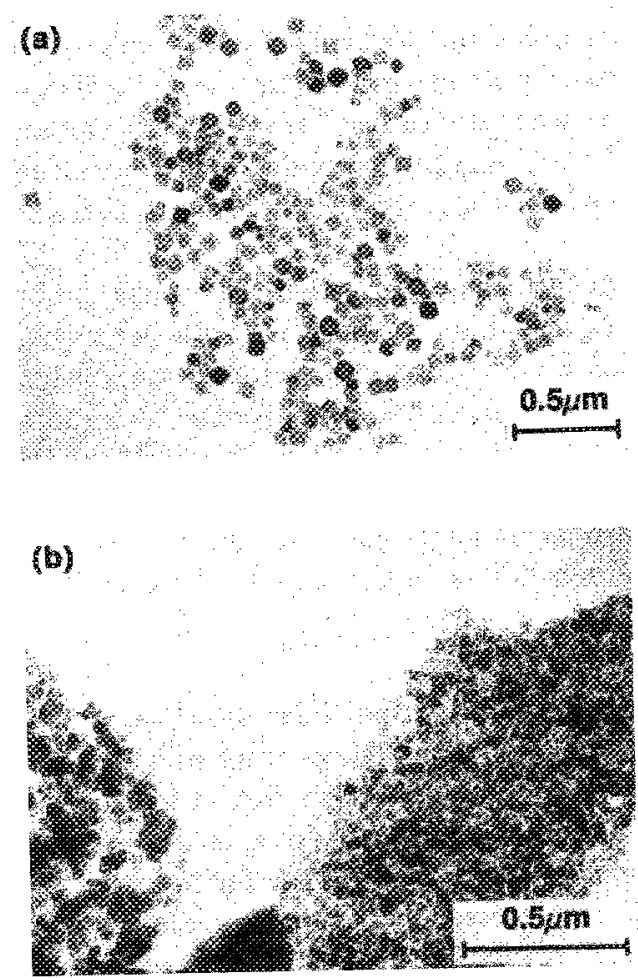

FIG. 4. TEM of $\mathrm{Na}_{2} \mathrm{SiO}_{3}$-coated (a) iron oxide and (b) metal particles. 
behavior in TEM micrographs. Several materials, including $\mathrm{Na}_{2} \mathrm{SiO}_{3}, \mathrm{PVA}$, silicic acid, and barium dodecyl salfonate have been tried as coating materials to prevent iron particles from sintering during hydrogen reduction. Of these, $\mathrm{Na}_{2} \mathrm{SiO}_{3}$ appears to be the most suitable. As shown in Fig. 3, the values of $H_{c}$ for particles with $\mathrm{Na}_{2} \mathrm{SiO}_{3}$ coating remain very high (about $1000 \mathrm{Oe}$ ) for a wide range of reduction temperatures. Even with hydrogen reduction at $500^{\circ} \mathrm{C}, H_{c}$ shows no sign of decreasing. Indeed, detailed electron micrographs of iron particles coated with $\mathrm{Na}_{2} \mathrm{SiO}_{3}$, as shown in Fig. 4 , indicate little or no sintering between the particles.

For particles coated with PVA and reduced at $500^{\circ} \mathrm{C}$, $H_{c}$ values are all below $200 \mathrm{Oe}$. In the case of silicic-acidcoated particles reduced at $500^{\circ} \mathrm{C}, H_{c}$ is even lower, at about 50 Oe. The TEM micrographs indicate that these particles have sintered into rodlike structures.

Two samples reduced at $400^{\circ} \mathrm{C}$ with barium dodecyl suifonate coating produced rather high $H_{c}$ yalues: 530 and 970 Oe. Barium dodecyl sulfonate appears to be also promising as a coating material.
In summary, we have succeeded in preparing pure submicron iron particles with uniform size and high coercivity. $\mathrm{Na}_{2} \mathrm{SiO}_{3}$ is found to be the best material for the process of reducing iron oxide particles to iron.

This work was supported in part by the office of Naval Research contract No. No0014-85-C-0637.

\footnotetext{
${ }^{3}$ A. A. Van der Giessen and C. J. Kcomp; IEEE Trans. Magn. MAG-\$, 317 (1969).

${ }^{2}$ M. Kawasaki and S. Higuchi, IEEE Trans. Magn. MAG-8, 430 (1972).

${ }^{3} \mathrm{O}$. Fujii and Y. Hiraga, Japanese Patent No. 58 (1983)-126906 (1983).

${ }^{4}$ T. Sreyoshi, K. Teshita, S. Hirai, M. Kishimoro, Y. Kayashi, and M. Amemiya, J. Appl. Phys. 53, 2570 (1982).

${ }^{5}$ K. Bridger, J. Warts, M. Tadros, Gang Xiao, S. H. Liou, and C. L. Chien, presented at MRS Fall Meeting, Boston (1986).

${ }^{6} \mathrm{E}$. Matijevic and $\mathrm{P}$. Scheiner, J. Colloid. Int. Sci. 63, 509 (1978).

${ }^{7} \mathrm{Y}$. Tokuoka, R. Horimoto, T. Kobuke, and H. Morita, Proceedings of the ICF-3, Third International Conference on Ferrites (Reidel, Dordrecht, 1982), p. 535

${ }^{2}$ E. F. Kneller and F. E. Luborsky, J. Appl. Phys. 34, 656 (1963).
} 